\title{
Academic Performance and Time Management of Medical Students in Saudi Arabia
}

\author{
Nivin Sharaf Eldin ${ }^{1}$, Akef Obeidat ${ }^{1}$, Gilles Jadd ${ }^{1}$, Mohamad Al-Tannir ${ }^{2,}$ Mahmoud Aly ${ }^{3,4}$ and \\ Khaled Alkattan ${ }^{1}$ \\ ${ }^{1}$ Faculty of medicine, Alfisal University, Riyadh, Saudi Arabia \\ ${ }^{2}$ Clinical and Applied Research Department, Research Centre, King Fahd medical city, \\ Riyadh, Saudi Arabia \\ ${ }^{3}$ King Abdullah International Medical Research Center \\ ${ }^{4}$ King Saud bin Abdulaziz University for Health Sciences \\ Riyadh, KSA
}

\begin{abstract}
Rational: The capability and willingness of students to develop and implement time management skills is crucial for a better academic performance and quality educational outcome. Over the last two decades, student mentorship has showed promising results to better prepare students for high academic performance through identifying their studying barriers and helping them apply the required corrective measures. Objective: The main objective of the current study is to explore students' different studying patterns and observe the learning behaviors among medical students in Saudi Arabia. Methods: Our methods include a questionnaire survey and student mentorship interviews. These tools aim to produce observational insights, awareness for student studying styles, capabilities for preforming the required corrective measures and accepting interventions. Students will then be re-evaluating their perceptions and academic performance. The modified questionnaire is based on an extensively tested and validated time management questionnaire of Kent University, UK. Data collection and statistical analysis will be carried out using SPSS VR20. Results: Many medical students volunteered to be involved in the current study. Our target is to recruit 100 subjects from the Saudi medical student. Between 2011- 2014 a total number of student involved in the current study were two hundred and twenty-one $(n=221)$, with 131 female students and 90 male. Moreover the descriptive stats for their GPA, one hundred and eighty-two $(n=182)$, were as the following: mean GPA of $3.29 \pm 0.03$ Standard Error, Median 3.40 \pm 0.45 Standard Deviation with a Minimum of 2.00 and Maximum GPA was 4.00. Most of the students, one hundred and ninety-four ( $n=194)$ spent average more than 4 hours in front of a screen $(4.70 \pm 0.29)$ with a median of $4.00 \pm 4.08$ hours and
\end{abstract}

minimum 0.50 a maximum 16.00 hours consisting mostly of TV time. The regular sleeping schedule followed by the subjects started from 11-1 pm. Females were more punctual and regular, 62 (47\%), unlike the males who were not as frequent, 44 (49.5\%). In regular wake up timings, from $6-8 \mathrm{AM}$ there are 53 (59.6\%) males and 57 (43.2\%) females who are found regular and punctual in wake up timings and this result is slightly significant ( $p$ $=0.045$ ) with the association between gender and regular wake up timings. Conclusions: Student's mental stress due to lack of proper time management and feelings of inadequacy to learn were identified as core barriers to achieve higher academic performances. Although we did not find any significant association between genders and regular timings, the responses of participants was changing their reference to regular timings. Here, we showed that proper mentorship, better time management and the identification of study pattern styles among students are clearly affecting the academic performance of the medical students in Saudi Arabia. More studies are required to improve Mentorship development program.

\section{Introduction}

Over the previous two years, Student Mentorship showed promising results to better prepare students for high academic performance through identifying studying barriers and taking the required corrective measures [1].The capability and willingness of students to develop and execute time management skills is crucial for better academic performance and educational quality outcome [2].

The academic transition between high school and university is regarded as a life event that involves 
various changes in students' usual patterns such as their behavior as pupils, their relationships with their new classmates, and the academic demands to which they must place into consideration [3]. Accordingly, students must endeavor to adapt, and are required to create sufficient methods to manage the new circumstances and academic criteria they are now confronting [3].

One of the biggest issues facing current medical students, is time management [3]. The criterion for efficient time management lies not only in achieving set goals, but also in attaining them in the least time possible. A crucial point is how to use the available time in the most efficient and effective way possible [9-11]. In fact, the challenge of imparting a large amount of knowledge within a limited time period is remembered and effectively interpreted by students is vast. This has resulted in crucial changes within the field of medical education, with a shift from didactic teacher-centered and subject-based teaching to the use of interactive, problem-based, studentcentered learning [12]. Most medical school curricula have adopted new methods of teaching and learning to varying degrees [13].

Several studies correlated academic performances to time management but unfortunately, very few studies have evaluated this correlation in the kingdom of Saudi Arabia. Since the capability and willingness of students to develop and implement time management skills is crucial for better academic performance and quality educational outcome, we undertook this study to explore the students' study patterns and attitudes and to evaluate their readiness for identifying major obstacles and resolving approaches in order to achieve better academic performance.

\section{Objectives}

The main objective of the current study is to explore the students' studying patterns, attitudes and to evaluate their capability of identifying major obstacles and resolving approaches

\section{Method}

In the current study we evaluated the time management, study style and sleep pattern of the students, particularly those with late sleep time, in relation to their academic performance measured by GPA. Moreover we explored the time spent behind technological screens and the outcome of GPA performance and finally we assessed the ability of student to study from more than one resource material and its effect on their GPA achievements.

\subsection{Questionnaire}

Our questionnaire was developed using LASSI (learning and study strategies inventory from the ten scales that are used as a basis for improving all students learning and study strategies [4] [5].

\subsection{TMT SCALE}

Time management scale that assesses the student's application time management principles to academic.

\subsection{Study population}

Two hundred and thirty-five first- and secondyear health sciences and medical students in Riyadh were invited to participate in this survey during July 2011 through November 2014

\subsection{Data collection}

Students were asked to fill a LASSI based questionnaire. The questions covered the important aspects in LASSI principles.

Questionnaires were distributed through students, volunteers, paid websites, emails and one on one interviews (see Figure1).

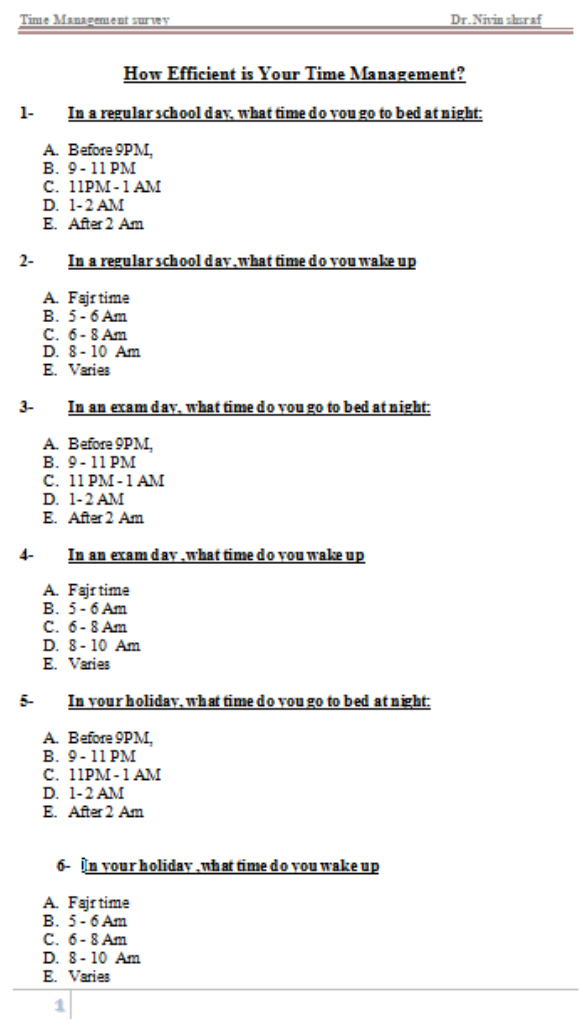

Figure 1. Image of the questionnaire answered by the volunteered student 


\subsection{Statistical analysis}

All categorical variables were presented as numbers and percentages. Chi-square or Fisher's exact test was used according to whether the cell expected frequency is smaller than five and determine the significant relationship or association among categorical variables. $\mathrm{P}$ - value of less than 0.05 was considered as statistically significant. Data was entered and analyzed through the statistical package SPSS, version 22.

\section{Results}

Our results showed that, the total number of student involved in the current study were two hundred and twenty-one $(n=221)$, with 131 female student and 90 male student. Additionally, the descriptive stats for their GPA one hundred and eighty-two $(n=182)$ were as follow: Mean GPA of $3.29 \pm 0.03$ Standard Error, Median 3.40 \pm 0.45 Standard Deviation with a Minimum of 2.00 and Maximum GPA was 4.00.

Most of the students, one hundred and ninetyfour $(n=194)$ spent average more than 4 hours in front of a screen $(4.70 \pm 0.29)$ with a median of 4.00 \pm 4.08 hours, a minimum of 0.50 and maximum16.00 hours mostly TV time.

\subsection{Gender association and regular timing}

Although we did not find any significant association between genders and their regular timings, the responses of participants were changing with reference to their regular timings. Their regular sleeping schedule started from $11-1 \mathrm{PM}$. There is frequent $44(49.5 \%)$ male but $62(47 \%)$ female are found punctual and regular. In regular wake up timings, from $6-8$ AM there are $53(59.6 \%)$ males and $57(43.2 \%)$ females are found regular and punctual in walkup timings and this result is slightly significant $(p=0.045)$ association between gender and regular wakeup timings (see Figure 2).

On the other hand, the analysis of the gender relationship with regular timings, study hours and sleeping habits, results showed that male students $\mathrm{n}=33(37.5 \%)$ and $63(47.7 \%)$ prefer to wake up early in comparison with female who wake up early. Significant $(p=0.009)$ association between gender and those who had fixed study timings. For seeking help while studying, $33(37.1 \%)$ male and 102 (77.3\%) female prefer to ask help from their friends and teachers.

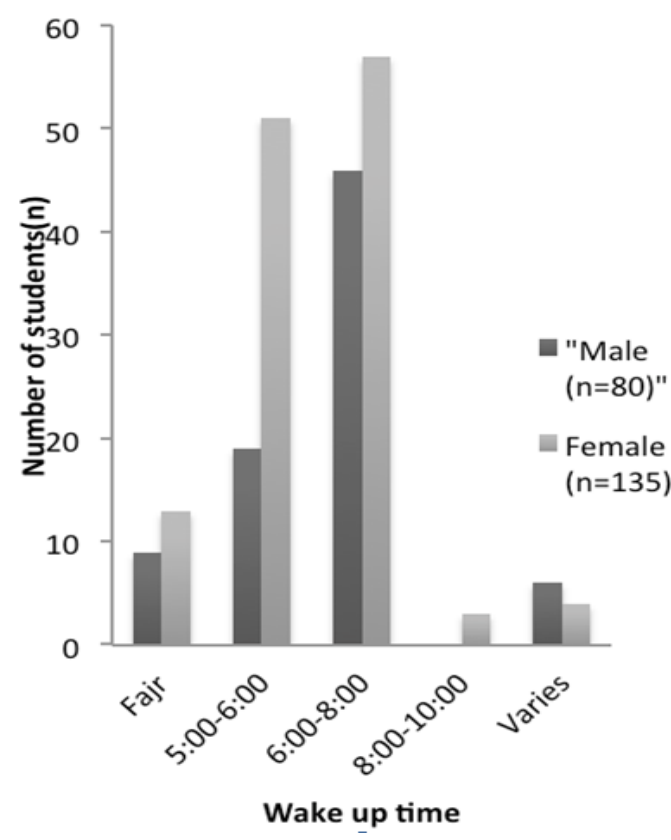

Figure 2. Gender relationship with regular waking up timings

This association is crucial for it is highly statistically significant $(\mathrm{P}<0.001)$.

\subsection{Gender Association with study time spending, GPA and other parameters}

There is statistically significant $(\mathrm{p}=0.002)$ association between GPA and gender. On the contrary, $34(25.8 \%)$ females and $21(23.6 \%)$ have more 3.5 GPA score and comparatively female are concerned with achieving high GPA scores.

Table 1. Gender relationship with Regular timings, study hours and sleeping habits

\begin{tabular}{|c|c|c|c|c|}
\hline Question & Answer & Male $\mathrm{n}(\%)$ & Female $\mathbf{n}(\%)$ & $P$-value \\
\hline \multirow{3}{*}{ Are you a } & Morning person & $33(37.5 \%)$ & $63(47.7 \%)$ & \multirow{3}{*}{0.297} \\
\hline & Evening person & $26(29.5 \%)$ & $30(22.7 \%)$ & \\
\hline & Don’t know & $29(33 \%)$ & $39(22.7 \%)$ & \\
\hline \multirow{3}{*}{ Do you live } & Alone & $9(9.1 \%)$ & $10(7.6 \%)$ & \multirow{3}{*}{0.371} \\
\hline & With family & $74(84.1 \%)$ & $118(89.4 \%)$ & \\
\hline & With friends & & $4(3.0 \%)$ & \\
\hline \multirow{5}{*}{$\begin{array}{l}\text { How many hours do you } \\
\text { study in regular school } \\
\text { day }\end{array}$} & Not every day & $21(23.9 \%)$ & $28(21.4 \%)$ & \multirow{5}{*}{0.335} \\
\hline & $1-2$ hours & $19(21.6 \%)$ & $29(22.1 \%)$ & \\
\hline & $3-5$ hours & $32(36.4 \%)$ & $51(38.9 \%)$ & \\
\hline & More than 6 hours & $4(4.5 \%)$ & $11(8.4 \%)$ & \\
\hline & Don’t know & $12(13.6 \%)$ & $12(9.2 \%)$ & \\
\hline \multirow{5}{*}{$\begin{array}{l}\text { How many hours do you } \\
\text { study in exam day }\end{array}$} & Not every day & $1(1.1 \%)$ & $2(1.5 \%)$ & \multirow{5}{*}{0.342} \\
\hline & $1-2$ hours & $2(2.3 \%)$ & $8(6.1 \%)$ & \\
\hline & $3-5$ hours & $16(18.2 \%)$ & $35(26.5 \%)$ & \\
\hline & More than 6 hours & $62(70.5 \%)$ & $79(59.8 \%)$ & \\
\hline & Don't know & $7(8.0 \%)$ & $8(6.1 \%)$ & \\
\hline \multirow{4}{*}{$\begin{array}{l}\text { Do you have fixed study } \\
\text { time? }\end{array}$} & Yes & $9(10.1 \%)$ & $19(14.4 \%)$ & \multirow{4}{*}{${ }^{*} 0.009$} \\
\hline & No & $71(79.8 \%)$ & $103(78 \%)$ & \\
\hline & Night & $6(6.7 \%)$ & $1(0.8 \%)$ & \\
\hline & Morning & $2(2.2 \%)$ & 0.0 & \\
\hline \multirow{3}{*}{$\begin{array}{l}\text { Do you ask for help } \\
\text { when you have difficulty } \\
\text { with a lecture? }\end{array}$} & Yes & $33(37.1 \%)$ & $102(7$ & \multirow{3}{*}{$*<0.001$} \\
\hline & $\begin{array}{l}\text { Friends } \\
\text { Teachers }\end{array}$ & $33(36.8 \%)$ & 0.0 & \\
\hline & No & $22(24.7 \%)$ & $30(22.7 \%)$ & \\
\hline
\end{tabular}


Similarly, we found statistically significant $(\mathrm{p}=$ 0.001 ) results between years of student and gender. Finally, females participate more in every aspect of educational activities and time management. The overview of the questionnaire was provided in the supplementary (see Table 1) for the perception and practical approach about time management information.

\section{Discussion}

Students who score low on this scale may need to develop effective scheduling and monitoring techniques in order to assure timely completion of academic tasks and to avoid procrastination while realistically including non-academic activities in their schedule.

Most time management programs and tips require broad or more significant life style changes than a medical student can handle, as most medical students interviewed stated, "No size fits all." However, more than forty students were interviewed through the student mentorship program and were introduced to gradual implementation of time management tips after documenting their learning strategies as well as their strengths and weaknesses.

Students who sought help through the mentorship program benefited from mentoring and achieved a higher GPA than those who did not.

\section{Conclusion}

In this paper we showed that proper mentorship, better time management and the identification of study pattern styles among students clearly affect the academic performance of medical students in Saudi Arabia. More studies are required to improve Mentorship development through time management program.

\section{References}

[1] Pagana, K.D., Teaching students time management strategies. The Journal of nursing education, 1994. 33(8): p. 381-3.

[2] Vancouver, J.B., et al., Testing for validity and bias in the use of GPA and the MCAT in the selection of medical school students. Academic medicine: journal of the Association of American Medical Colleges, 1990. 65(11): p. 69

[3] Zhou, Y.X., et al., Predictors of first-year GPA of medical students: a longitudinal study of 1285 matriculates in China. BMC medical education, 2014. 14: p. 87.

[4] Flowers, L.A., B.K. Bridges, and I.J. Moore, Concurrent validity of the Learning and Study Strategies Inventory (LASSI): a study of African American precollege students. Journal of black studies, 2012. 43(2): p. 146-60.

[5] Pringle, R.K. and J. Lee, The use of Learning and Study Strategies Inventory (LASSI) as a predictor for success or failure on part I of the National Board of Chiropractic Examiners Test. Journal of manipulative and physiological therapeutics, 1998. 21(3): p. 164-6.

[6] Cleary, M. and J. Horsfall, Developing students' time management skills in clinical settings: practical considerations for busy nursing staff. Journal of continuing education in nursing, 2011. 42(6): p. 248-9.

[7] Bembenutty, H., Academic delay of gratification, selfefficacy, and time management among academically unprepared college students. Psychological reports, 2009. 104(2): p. 613-23.

[8] Henry, A.D., et al., Time use, time management and academic achievement among occupational therapy students. Work, 1996. 6(2): p. 115-26.

[9] Madjar, N., T. Kushnir, and Y.G. Bachner, Communication skills training in medical students: Do motivational orientations predict changes over time in psychosocial attributes? Advances in health sciences education: theory and practice, 2014.

[10] Rosanowski, F., U. Eysholdt, and U. Hoppe, Influence of leisure-time noise on outer hair cell activity in medical students. International archives of occupational and environmental health, 2006. 80(1): p. 25-31.

[11] Covic, T., et al., Health science students' time organization and management skills: a cross-disciplinary investigation. Medical teacher, 2003. 25(1): p. 47-53.

[12] Gruppen, L.D., et al., Medical students' selfassessments and their allocations of learning time. Academic medicine: journal of the Association of American Medical Colleges, 2000. 75(4): p. 374-9.

[13] Spoelstra, H., et al., Convergence and translation: attitudes to inter-professional learning and teaching of creative problem-solving among medical and engineering students and staff. BMC medical education, 2014. 14: p. 14.

[14] Koh, G.C., et al., The effects of problem-based learning during medical school on physician competency: a systematic review. CMAJ: Canadian Medical Association journal $=$ journal de l'Association medicale canadienne, 2008. 178(1): p. 34-41. 